\title{
Alcohol Use During Pregnancy and Associated Factors Among Pregnant Women in Sub-saharan Africa: Further Analysis of the Recent Demographic and Health Survey Data
}

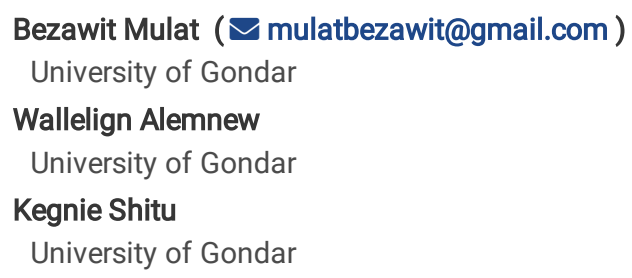




\section{Abstract}

Background

Alcohol drinking during pregnancy is towering in spite of the well-established prove on

its unfavorable pregnancy results and destitute child improvement. Despite such enormous consequences, there are limited data that explore about the extent of alcohol drinking and its associated factors among mothers during pregnancy in sub-Saharan Africa.

Objective

This study aimed to assess the prevalence and associated factors of alcohol consumption during pregnancy among pregnant mothers in subSaharan Africa.

Method

A community based crossectional demographic and health survey was conducted from 2013 to 2017 among four Sub-Sahara African countries: Burundi, Ethiopia, Liberia and Zimbabwe. A two-stage stratified sampling technique was employed to select the participants. Multivariable Logistic regression analysis was used to identify factors associated with alcohol consumption during pregnancy. A p-value less than 0.05 and $95 \%$ confidence interval were used to declare statistical significance.

Result

A total of 3,953 weighed sample of pregnant mothers were included in the study. The mean age of the participants was 27.3 ( \pm 6.8 ) years with an age range of $15-49$ years. The overall prevalence of alcohol use during pregnancy was $22.8 \%$ with $(95 \% \mathrm{Cl}(21.5,24))$ and it was significantly associated with increased age $(A O R=1.02,95 \% \mathrm{Cl}(1.01,1.04)$ ), Muslim religion follower ( $A O R=0.07,95 \%(0.05,0.11)$, husband/partner's educational status of primary $(\mathrm{AOR}=0.7,95 \% \mathrm{Cl}(0.55,0.84)$, secondary $(\mathrm{AOR}=0.53,95 \% \mathrm{Cl}(0.41,0.7))$ and higher $(\mathrm{AOR}=0.49,95 \% \mathrm{Cl}(0.31,0.8)$, being currently working $(A O R=1.5,95 \% \mathrm{Cl}(1.09,1.55)$, having $A N C$ visit $(A O R=0.82,95 \% \mathrm{Cl}(0.68,0.98)$ and increased gravidity $(\mathrm{AOR}=0.93,95 \% \mathrm{Cl}(0.86,0.99)$.

Conclusion

Alcohol drinking during pregnancy was high among pregnants in sub-Saharan African countries. Maternal age, religion, husband educational status, current working status of the mother, presence of ANC visit and gravidity of the mother were factors which have significant association with alcohol drinking during pregnancy. This calls a tailored behavior change intervention to reduce alcohol use during pregnancy. More emphasis should also be given for pregnant women with no ANC visit, lower gravidity, and an illiterate husband, currently working and Christianity followers.

\section{Background}

Alcohol is a psychotropic agent that can have acute and chronic impacts on brain functions (1). Alcohol consumption during pregnancy is a significant public health problem. It has a number of negative effects on maternal and fetal health (2). To begin with, alcohol crosses the placenta quickly, with fetal blood alcohol levels surpassing maternal levels within 2 hours of maternal admission, affecting fetal development immediately (3). Second, alcohol consumption during pregnancy may have an indirect effect on fetal development by altering the mother-fetus hormonal connections (4). According to a World Health Organization research on alcohol use, there is no safe level of alcohol consumption during pregnancy. Furthermore, it states that alcohol is the most prevalent teratogen and dangerous chemical, and that there is no safe period or amount of alcohol to consume during pregnancy (5). On the report of the World Health Organization (WHO), sub-Saharan Africa (SSA) has one of the highest per capita rates of alcohol consumption in the world, implying a high prevalence of Fetal Alcohol Spectrum Disorder $(F A S D)$ in the region $(5,6)$. Drinking alcohol is known to cause preventable cognitive impairment in both the child and the mother $(7,8)$. One of the few preventable and modifiable risk factors for poor pregnancy and birth outcomes is alcohol consumption during pregnancy (9). Miscarriage, stillbirth, early birth, congenital abnormalities, intrauterine growth retardation, and low birth weight are all possible side effects. FASD is the most serious condition caused by excessive alcohol drinking during pregnancy (10). FASD is a catch-all name for a variety of negative consequences on the developing baby caused by alcohol consumption during pregnancy (11). It includes atypical facial features known as the philtrum, a small head circumference, lower than usual height, low body weight, poor coordination, and Attention Deficit Hyperactivity Disorder (ADHD) (12).

As stated by a paper published in the Lancet Global Health, the global prevalence of alcohol consumption during pregnancy and the occurrence of fetal alcohol spectrum disease is $9.8 \%$ and 14.6 cases per 10,000 people, respectively (13).

Women in Chad, Namibia, Uganda, and Ethiopia are the world's biggest alcohol drinkers, consuming 17.7 to 24.5 liters of pure alcohol per capita per year (14). The prevalence of alcohol drinking during pregnancy varies from $2.5 \%$ (15) to 59.28\% (15), according to researchers conducted in SubSaharan African nations. Self-reported alcohol use during pregnancy was found to be 18.5 percent in a study done in Burkina Faso (16). Unplanned pregnancy (17), a lack of awareness about the effects of alcohol consumption (18), having partners and friends consume alcohol (19), health-related problems such as depression (20) and unemployment (17) are the main factors for alcohol consumption during pregnancy in Sub-Saharan Africa. 
Despite the fact that alcohol drinking during pregnancy has been shown to be harmful to both the child and the mother's health, there is a scarcity of evidence in Sub-Saharan Africa. As a result, the goal of this study is to determine the overall prevalence of alcohol intake among pregnant women in Sub-Saharan Africa, as well as its associated characteristics. In addition, the current study is thought to provide crucial evidence for policymakers and program implementers in SSA to avoid alcohol use during pregnancy. Can be utilized as an input to strengthen stakeholder and clinical practitioners' efforts to raise awareness among pregnant women about their health outcomes in both the short and long term.

\section{Methods}

\section{Data source}

This study was based on the most recent Demographic Health Survey (DHS) data from four sub-Saharan African countries: Burundi in 2016-2017, Ethiopia, in 2016, Liberia in 2013 and Zimbabwe in 2015. A total of 33 Demographic and Health Surveys (DHSs) was conducted in SSA from 2010 to 2018. Of these only nine countries were measured alcohol use during pregnancy. However, only four of the nine countries measure alcohol intake during pregnancy in the same way: alcohol intake in the past one month. Therefore, only these four countries were included in the final analysis of the present study, while five of the countries were excluded since they had measured the outcome of interest with no clear/different time frame. Each country's DHS follows the same execution procedure. A two-stage stratified sampling procedure was used to select study participants in the DHS survey. Initially, Enumerations Areas (EAs) were selected based on the sampling frame of each respective country. In the second stage, a sample of households was selected from each EAs. The detailed sampling procedure used by DHS has been documented elsewhere (21)(22) (22). Individual records data set (IR file) were used for this study amongst the five DHS datasets. This data set (IR file) is consist of information collected from all eligible women aged 15-49 years. However, this study was limited to women who were pregnant during the survey. Given this, a total weighted sample of 3,953 current pregnant women aged 15-49 years were included in the study form four sub-Sahara African countries (Figure 1).

\section{Study variables}

\section{Dependent variable}

The outcome variable of this study was alcohol drinking during pregnancy among pregnant mothers in sub-Saharan Africa. The variable was dichotomized into $\mathbf{1}$ = "drink alcohol during pregnancy" and $\mathbf{0}$ = "didn't drink alcohol during pregnancy".

\section{Independent variables}

In this study the independent variables included: sociodemographic factors (Age, religion, residence, marital status, educational status of the mother, educational status of husband/partner, and current working (employment) status, and obstetric factors: complications during previous pregnancies (terminated pregnancy), pregnancy plan, and gravidity (number of pregnancy).

\section{Operational definitions}

Alcohol drinking during pregnancy: This was defined as consumption of any alcohol containing drink during pregnancy. It was assessed by asking pregnant mothers whether they took alcohol in the past one month.

Household wealth quintile: The wealth index was divided into quintiles: poorest, poor, middle, rich, and richest. Principal component analysis were used to arrive at these results (PCA). By combining the lower two (poorest and poor) quantiles with the top two (richest and rich) quantiles, this variable was further divided into three categories (Poor, Medium, and rich) (23).

Media Exposure: This variable was computed from the frequency of exposure to the two commonest mass media routes (radio and television). In this study exposure to magazines/newspapers was excluded because little $(<5 \%)$ women were exposed to this channel. The variable was categorized into two parts: no exposure to media and had exposure to media.

\section{Data processing and Analysis}

Individual records (IR) files were used to extract data, which was then coded and transformed using STATA version 14 statistical software. To account for differential chance of selection and non-response in the original survey, weighted samples were employed for analysis. The presence of statistical significance was determined using a multivariable logistic regression analysis. It was fitted after the model's fitness was evaluated using the Hosmer and Lemeshow goodness of fit test. The variance inflation factor (VIF) was also used to analyze multicollinearity across the explanatory components, and it was found to be within acceptable limits. A p-value less than 0.05 is used to evaluate the presence of a meaningful effect or relationship of independent factors with the outcome variable.

\section{Result}


A total of 3,953 pregnant mothers were included in the study. The mean age of the participants was 27.3 ( \pm 6.8$)$ years with an age range of $15-49$ years. The majority (67.9\%) of the mothers were Christians and more than half of them (71\%) were married and 2,938 (75\%) were from a rural area. Concerning the reproductive history, about $90.2 \%$ (3565) had wanted pregnancy and (55.7\%) of pregnant mothers have ANC visits. (Table 1 )

Table 1

Sociodemographic and obstetric characteristics of pregnant women in sub-Saharan African countries $(n=3,953)$

\begin{tabular}{|c|c|c|c|}
\hline Variable & Category & Frequency & Percent \\
\hline \multirow[t]{3}{*}{ Age (in years) } & $15-24$ & 1445 & 36.6 \\
\hline & $25-34$ & 1861 & 47.0 \\
\hline & $35-49$ & 647 & 16.4 \\
\hline \multirow[t]{2}{*}{ Marital status } & Single & 1145 & 29.0 \\
\hline & Married & 2808 & 71.0 \\
\hline \multirow[t]{2}{*}{ Residence } & Rural & 3039 & 77.0 \\
\hline & Urban & 914 & 23.0 \\
\hline \multirow[t]{4}{*}{ Educational status of respondents } & No formal education & 1509 & 38.2 \\
\hline & Primary & 1487 & 37.6 \\
\hline & Secondary & 850 & 21.5 \\
\hline & Higher & 107 & 2.7 \\
\hline \multirow[t]{5}{*}{ Educational status of the husband/partner } & No formal education & 1097 & 28.0 \\
\hline & Primary & 1349 & 34.0 \\
\hline & Secondary & 964 & 24.3 \\
\hline & Higher & 179 & 4.5 \\
\hline & Don't know & 364 & 9.2 \\
\hline \multirow[t]{3}{*}{ Wealth index } & Poor & 1706 & 43.0 \\
\hline & Medium & 785 & 20.0 \\
\hline & Rich & 1462 & 37.0 \\
\hline \multirow[t]{2}{*}{ Current working status } & Currently working & 2099 & 53.1 \\
\hline & Currently not working & 1854 & 46.9 \\
\hline \multirow[t]{2}{*}{ Mass media exposure } & Have exposure & 1251 & 31.7 \\
\hline & Haven't exposure & 2702 & 68.3 \\
\hline \multirow[t]{2}{*}{ Current pregnancy wanted } & Wanted & 3565 & 90.2 \\
\hline & Unwanted & 388 & 9.8 \\
\hline Gravidity ${ }^{c}$ & $3(2-5)^{\neq}$ & & \\
\hline \multirow[t]{2}{*}{ Have ANC visit } & Yes & 2201 & 55.7 \\
\hline & No & 1752 & 44.3 \\
\hline \multirow[t]{2}{*}{ Ever had terminated pregnancy } & Yes & 625 & 15.8 \\
\hline & No & 3328 & 84.2 \\
\hline
\end{tabular}

Alcohol Use During Pregnancy>

In this study the overall prevalence of alcohol drinking during pregnancy was $22.8 \%$ with (95\% $\mathrm{Cl}(21.5,24))$. Without taking into account population weighting, the prevalence of alcohol drinking during pregnancy for all four countries was $21.7 \%$. The prevalence of alcohol consumption among pregnant mothers was high in Brundi (32.4\%) and low in Zimbabwe (3\%\%). (Figure 2). 
The proportion of alcohol drinking was higher among mothers who are residents of rural area that is $24 \%$ as compared to urban resident mothers (18\%). Moreover, the proportion of mothers who drink alcohol during pregnancy is higher among older age groups (35-49) years. Additionally, the proportion of alcohol drinking is higher (27.4\%) among mothers who hadn't formal educational attainment as compared to mothers who were taking part in formal education. In addition to the aforementioned factors, the proportion of pregnant mothers who drank alcohol was higher among single mothers as compared to married once.

\section{Factors associated with alcohol drinking during pregnancy}

Based on the output of multivariable binary logistic regression analysis the following explanatory variables had a statistically significant association with alcohol drinking during pregnancy: increased age (AOR=1.02, 95\% $\mathrm{Cl}(1.01,1.04)$ ), being Muslim religion follower (AOR=0.07, 95\% $\mathrm{Cl}(0.05$,

0.11)), Husband education (husbands who attended primary educational level ( $A O R=0.7,95 \% \mathrm{Cl}(0.55,0.84)$, have secondary level educational status $(A O R=0.53,95 \% \mathrm{Cl}(0.41,0.7))$, husbands who attended higher educational levels $(\mathrm{AOR}=0.49,95 \% \mathrm{Cl}(0.31,0.8)$. Plus to the above factors being currently working (AOR= $1.3,95 \% \mathrm{Cl}(1.08,1.55)$ ), gravidity $(\mathrm{AOR}=0.92,95 \% \mathrm{Cl}(0.87,0.99)$, and having $\mathrm{ANC}$ visit $(\mathrm{AOR}=0.52,95 \% \mathrm{Cl}(0.68,0.98)$ were significantly associated with mothers alcohol drinking during pregnancy.

The odds of drinking alcohol during pregnancy was increased by $2 \%$ as the age of the mother increased by a year. The odds of drinking alcohol during pregnancy were $97 \%$ lower among Muslim pregnant mothers as compared to Christian pregnant mothers. Moreover, having a husband with primary, secondary and higher education level decreased the odds of drinking alcohol during pregnancy by $30 \%, 47 \%$ and $51 \%$ respectively, when compared to pregnant mothers having an illiterate husband. (Table 2) 
Table 2

Factors associated with alcohol use during pregnancy among pregnant mothers in sub-Saharan African countries, ( $n=3,953$ ).

\begin{tabular}{|c|c|c|c|}
\hline \multirow[t]{2}{*}{ Variable } & \multicolumn{2}{|c|}{ Alcohol drinking during pregnancy } & \multirow[t]{2}{*}{ AOR } \\
\hline & Yes $(n=901)$ & $\mathrm{No}(\mathrm{n}=3,052)$ & \\
\hline & Frequency (\%) & Frequency $(\%)$ & \\
\hline $\mathrm{Age}^{\mathrm{c}}$ & $28(23-33)^{\mu}$ & $26(22-32)^{\mu}$ & $1.02(1.05,1.04) *$ \\
\hline \multicolumn{4}{|l|}{ Marital status } \\
\hline Single & $294(25.7 \%)$ & $851(74.3 \%)$ & 1 \\
\hline Married & $606(21.6 \%)$ & 2201(78.4\%) & $1.08(0.9,1.3)$ \\
\hline \multicolumn{4}{|l|}{ Residence } \\
\hline Urban & $167(18.3 \%)$ & $747(81.7 \%)$ & 1 \\
\hline Rural & $734(24 \%)$ & $2305(76 \%)$ & $1.17(0.92,1.5)$ \\
\hline \multicolumn{4}{|l|}{ Religion } \\
\hline Christian & $848(30.5 \%)$ & $1935(69.5 \%)$ & 1 \\
\hline Muslim & $22(3 \%)$ & $694997 \%)$ & $0.07(0.05,0.11) *$ \\
\hline Other & $31(6.8 \%)$ & $423(93.2 \%)$ & $0.24(0.16,0.35) *$ \\
\hline \multicolumn{4}{|c|}{ Mothers educational level } \\
\hline No formal education & $414(27 \%)$ & $1,095(73 \%)$ & 1 \\
\hline Primary & $354(23.8 \%)$ & $1,133(76.2 \%)$ & $1.07(0.9,1.3)$ \\
\hline Secondary & $116(13.7 \%)$ & $733(86.3 \%)$ & $0.92(0.69,1.24)$ \\
\hline Higher & $17(15.8 \%)$ & $90(84.2 \%)$ & $1.03(0.57,1.9)$ \\
\hline \multicolumn{4}{|l|}{ Current working status } \\
\hline Currently working & $581(28 \%)$ & $1519(72 \%)$ & $1.3(1.09,1.55) *$ \\
\hline Currently not working & $320(17.3 \%)$ & $1533(82.7 \%)$ & 1 \\
\hline \multicolumn{4}{|l|}{ Husband education } \\
\hline No formal education & $336(30.6 \%)$ & $761(69.4 \%)$ & 1 \\
\hline Primary education & $305(22.6 \%)$ & $1,044(77.4 \%)$ & $0.7(0.55,0.84) *$ \\
\hline Secondary education & $136(14 \%)$ & $828(86 \%)$ & $0.53(0.41,0.69)$ * \\
\hline Higher & $31(17 \%)$ & $149(83 \%)$ & $0.5(0.3,0.82) *$ \\
\hline Don't know & $93(25.6 \%)$ & $271(74.4 \%)$ & $0.68(0.47,0.97)$ * \\
\hline \multicolumn{4}{|l|}{ Wealth index } \\
\hline Poor & $403(23.6 \%)$ & $1302(76.4 \%)$ & 1 \\
\hline Medium & $191(24.3 \%)$ & $595(75.7 \%)$ & $1.1(0.9,1.4)$ \\
\hline Rich & $307(21 \%)$ & $1155(79 \%)$ & $1.06(0.85,1.3)$ \\
\hline \multicolumn{4}{|l|}{ Media exposure } \\
\hline Exposed & $666(24.7 \%)$ & $2036(75.3 \%)$ & $0.98(0.8,1.2)$ \\
\hline Non exposed & 235(19\%) & $1016(81 \%)$ & 1 \\
\hline \multicolumn{4}{|l|}{ Current pregnancy } \\
\hline Wanted & $804(22.6) \%$ & $2761(77.5 \%)$ & $0.95(0.7,1.3)$ \\
\hline Unwanted & $97(25 \%)$ & $291(75 \%)$ & 1 \\
\hline Have ANC visits & & & \\
\hline
\end{tabular}

Key : $c$ ( continuous $), \mu($ mean with standard deviation,$\neq($ Median with interquartile range $)$ *( statistically significant $(p$ value $<0.05)$ 


\begin{tabular}{|llll|}
\hline Variable & \multicolumn{1}{l|}{ Alcohol drinking during pregnancy } & AOR \\
\hline Yes & $527(24 \%)$ & $1674(76 \%)$ & $0.82(0.68,0.98)^{*}$ \\
\hline No & $373(21.3 \%)$ & $1378(78.7 \%)$ & 1 \\
\hline Ever had terminated pregnancy & & & \\
\hline Yes & $165(26.5 \%)$ & $460(73.5 \%)$ & $1.17(0.93,1.5)$ \\
\hline No & $735(22.1 \%)$ & $2592(77.9 \%)$ & 1 \\
\hline Gravidityc & $3(2-5)^{\neq}$ & $3(2-5)^{\neq}$ & $0.93(0.86,0.99)^{*}$ \\
\hline Key : $c$ (continuous $), \mu\left(\right.$ mean with standard deviation,$\neq\left(\right.$ Median with interquartile range), ${ }^{*}$ (statistically significant $(p$ value $<0.05)$ \\
\hline
\end{tabular}

\section{Discussion}

This study assessed the prevalence and associated factors of alcohol drinking during pregnancy among pregnant women in sub-Saharan Africa by analyzing the recent DHS data of the eligible 4 countries in the region. The overall prevalence of alcohol drinking during pregnancy is 22.8 with $95 \%$ $\mathrm{Cl}(21.5,24)$. The result is in line with the study conducted in Northern Uganda (23.6\%) (24). The possible explanation for this alignment might be the presence of similar socio-demographic characteristic of the respondents. However, the result of the present study is lower than a study conducted in UK (28.5\%), Russia (26.5\%) (25) and in Nigeria(59.29\%) (15). The discrepancy might be elucidated by difference in the economic status of mothers residing in Europe and African continent. The possible justification for the divergence would be women from the westerns life style, stress management ways, individualism and greater chance to access alcoholic beverages may be the factors which create this discrepancies. Due to this the prevalence of alcohol drinking among women in in sub-Saharan Africa is lower than European once. On the other hand the result of current study is higher than contemporary meta-analysis in sub-Saharan Africa (20.8\%) (26), the World Health Organization Africa region (18.5\% (14), Korea (16.4\%) (27)and Burkina Faso (18.5\%) (16). The disparity might be due to differences in study design and variations in population characteristics.

Alcohol drinking during pregnancy can be affected by different socio-demographic and obstetric characteristics of the mother. In the current study, alcohol drinking during pregnancy was significantly associated with increased age, which is supported by a study conducted in Sweden (28), Uganda (19) and Tanzania (29) .According to the findings of the present study the prevalence of alcohol drinking during pregnancy increased among Christians and being Muslim is a protective from consuming alcohol this result is in harmony with the study conducted in Tanzania (29). This implied that Women whose religion explicitly prohibited alcohol consumption have a decreased probability of consuming alcohol consumption and concomitantly minimize the chance of alcohol drinking when they became pregnant). Moreover, current working status of a mother is also significantly associated with alcohol drinking during pregnancy which is supported by a study conducted in Uganda (19) and Zambia (30). This implied that as the mother is involved in work (employed) she can able to generate income and the probability of buying and drinking alcoholic beverages is concomitantly increased. The educational status of husband was also another factor which is significantly associated with alcohol drinking during pregnancy, which is supported by a study conducted in Gondar town, Ethiopia (31). The feasible reason for this association might be husbands' educational status plays awesome part in decision-making power and had an indeed more noteworthy impact than did wives' education level on maternal health service decisions in developing countries $(32,33)$. Consequently, husbands with high educational status might have sufficient knowledge on adverse effects of alcohol use during pregnancy on maternal and fetal health. The result of the present study also revealed that pregnant mothers who had of anti-natal care (ANC) have decreased risk for consuming alcohol during pregnancy than their counter parts. And this finding is held up by the study done in Zambia (30). Finally, the present study also declared the presence of statistically significant association between alcohol drinking during pregnancy and womens' number of pregnancy (gravidity). This may explained as number of pregnancies increased the chance of the mother to visit health institutions might be increased so the mother had a greater chance to get information about the effect of alcohol drinking on the fetus and in general on pregnancy outcomes.

\section{Conclusion And Recommendations}

The present study revealed that the prevalence alcohol consumption during pregnancy is high among women's' living in Sub-Saharan Africa. Maternal age, religion, husbands' level of education, current working status of the mother, presence of ANC visits and increased maternal gravidity are factors significantly associated with mothers' alcohol drinking during pregnancy. Thus, Health education programs should be designed to minimize the consumption of alcohol during pregnancy in order to overcome the unfavorable outcomes that are caused by alcohol consumption on pregnancy and fetal health.

\section{Abbreviations}

ANC: Antenatal care, DHS: Demographic and Health Survey, AOR: Adjusted Odds Ratio, and FASD: Fetal Alcohol Spectrum Disorder

\section{Declarations}


Ethics approval and consent to participate

The study was conducted under the Declaration of Helsinki. Since the study was based on a secondary data (DHS data), the investigators were requested and get a permission letter to download and use the data files for the present study.

Consent for publication

Not applicable.

Availability of data and materials

All result-based data are available within the manuscript and anyone can access the data set online from www.measuredhs.com

Competing interests

The authors declare that they have no competing interests

Funding

No, any funding was received from any organization.

Authors' contributions

All authors made substantial contributions to conception, acquisition of data, or analysis and interpretation of data; took part in drafting the article or revising it critically for important intellectual content; agreed to submit to the current journal; gave final approval of the version to be published; and agree to be accountable for all aspects of the work.

Acknowledgments

We would like to acknowledge the MEASURE DHS program for permitting us to obtain and use DHS data sets of Sub-Saharan Africa.

\section{References}

1. Hartney E. The Different Types of Psychoactive Drugs [Internet]. Very Well Mind. 2020. Available from: https://www.verywellmind.com/what-ispsychoactive-22500

2. Ababa A. The prevalence and associated factors of alcohol use among pregnant women attending antenatal care at public hospitals. 2020;110.

3. Drinking A, Implications G. At-Risk Drinking and Alcohol Dependence: Obstetric and Gynecologic Implications. 2011;(496).

4. Gabriel K, Hofmann C, Glavas M, Weinberg J. The hormonal effects of alcohol use on the mother and fetus. Alcohol Res Heal. 1998;22(3):1707.

5. OMS (Organización Mundial de la Salud). Global status report on alcohol and health. World Heal Organ [Internet]. 2011; Available from: http://www.who.int/substance_abuse/publications/global_status_report_2004_overview.pdf

6. Martinez P, Røislien J, Naidoo N, Clausen T. Alcohol abstinence and drinking among African women: data from the World Health Surveys. 2011;

7. Mulat B, Ambelu A, Yitayih S, Gela YY, Adera A, Yeshaw Y, et al. Cognitive impairment and associated factors among adult hypothyroid patients in referral hospitals, amhara region, ethiopia: Multicenter cross-sectional study. Neuropsychiatr Dis Treat. 2021;17:935-43.

8. Oei JL. Alcohol use in pregnancy and its impact on the mother and child. Addiction. 2020;115(11):2148-63.

9. Asamoah BO, Agardh A. Alcohol consumption in relation to maternal deaths from induced-abortions in Ghana. 2012;2008:1-9.

10. Hoyme HE, May PA, Kalberg WO, Kodituwakku P, Gossage JP, Trujillo PM, et al. A Practical Clinical Approach to Diagnosis of Fetal Alcohol Spectrum Disorders: Clarification of the 1996 Institute of Medicine Criteria. 2015;115(1).

11. Information ER, Literature AH. Global Prevalence of Fetal Alcohol Spectrum Disorder Among Children and Youth A Systematic Review and Meta-analysis. 2017;171(10):948-56.

12. Scale AA, Index V, Frequency Q, Index V. Naturalistic 0 bservations of Newborns: Effects of Maternal Alcohol Intake. 1978;2(2):171-7. 
13. Tsang TW, Elliott EJ. High global prevalence of alcohol use during pregnancy and fetal alcohol syndrome indicates need for urgent action. Lancet Glob Heal [Intemet]. 2017;5(3):e232-3. Available from: http://dx.doi.org/10.1016/S2214-109X(17)30008-6

14. Popova S, Lange S, Probst C, Shield $\mathrm{K}$, Kraicer-melamed $\mathrm{H}$. Actual and predicted prevalence of alcohol consumption during pregnancy in the WHO African Region. 2016;00(00):1-31.

15. Ordinioha B. Alcohol consumption among pregnant women attending the ante-natal clinic of a tertiary hospital in South-South Nigeria. 2015; (January).

16. Sanou AS, Diallo AH, Holding P, Nankabirwa V, Engebretsen IMS, Ndeezi G, et al. Maternal alcohol consumption during pregnancy and child's cognitive performance at 6-8 years of age in rural Burkina Faso: An observational study. PeerJ. 2017;2017(6):1-23.

17. Anteab K, Demtsu B, Megra M. Assessment of Prevalence and Associated Factors of Alcohol Use during Pregnancy among the dwellers of Bahir-Dar City ,. 2014;5(12):939-46.

18. Morojele NK, London L, Olorunju SA, Matjila MJ, Davids AS, Rendall-Mkosi KM. Predictors of risk of alcohol-exposed pregnancies among women in an urban and a rural area of South Africa. Soc Sci Med [Internet]. 2010;70(4):534-42. Available from:

http://dx.doi.org/10.1016/j.socscimed.2009.10.040

19. Namagembe I, Jackson LW, Zullo MD, Frank SH, Byamugisha JK, Sethi AK. Consumption of alcoholic beverages among pregnant urban Ugandan women. Matern Child Health J. 2010;14(4):492-500.

20. Hartley M, Tomlinson M, Greco E, Comulada WS, Stewart J, le Roux I, et al. Depressed mood in pregnancy: prevalence and correlates in two Cape Town peri-urban settlements. Reprod Health. 2011;8:9.

21. Alawadhi A, Palin V, Staa T Van. Prevalence and factors associated with missed hospital appointments: a retrospective review of multiple clinics at Royal Hospital , Sultanate of Oman. BMJ Open. 2021;11:1-9.

22. The Demographic and Health Surveys (DHS) Program. http:// dhsprogram.com/What-We-Do/Survey-Types/DHS-Methodology.cfm.

23. Alemnew W, Mulat B, Shitu K. Women's Awareness of Obstetric Fistula and its Associated Factors Among Reproductive-Age Women in Ethiopia: A Multilevel Analysis Based on National Survey Data. medRxiv [Internet]. 2021;2021.04.29.21256293. Available from: https://www.medrxiv.org/content/10.1101/2021.04.29.21256293v1\%0Ahttps://www.medrxiv.org/content/10.1101/2021.04.29.21256293v1.abstract

24. Agiresaasi A, Nassanga G, Maina GW, Kiguli J, Nabiwemba E. Various forms of alcohol use and their predictors among pregnant women in post conflict northern Uganda: a cross sectional study. 2021;8:1-12.

25. Mårdby A, Lupattelli A, Hensing G, Nordeng H. Consumption of alcohol during pregnancy - A multinational European study. Women and Birth [Internet]. 2017;30(4):e207-13. Available from: http://dx.doi.org/10.1016/j.wombi.2017.01.003

26. Addila AE, Bisetegn TA, Gete YK, Mengistu MY. Alcohol consumption and its associated factors among pregnant women in Sub- Saharan Africa: a systematic review and meta-analysis ' as given in the submission system. 2020;3:1-14.

27. Lee SH, Won S. Alcohol Use during Pregnancy and Related Risk Factors in Korea. 2010;86-92.

28. Skagerström J, Alehagen S, Häggström-Nordin E, Årestedt K, Nilsen P. Prevalence of alcohol use before and during pregnancy and predictors of drinking during pregnancy: A cross sectional study in Sweden. BMC Public Health. 2013;13(1).

29. Isaksen AB, Østbye T, Mmbaga BT, Daltveit AK. Alcohol consumption among pregnant women in Northern Tanzania 2000-2010: A registrybased study. BMC Pregnancy Childbirth [Internet]. 2015;15(1):1-10. Available from: http://dx.doi.org/10.1186/s12884-015-0630-0

30. Moise IK. Alcohol use, pregnancy and associated risk factors: A pilot cross-sectional study of pregnant women attending prenatal care in an urban city. BMC Pregnancy Childbirth. 2019;19(1):1-7.

31. Addila AE, Azale T, Gete YK, Yitayal M. Determinants of hazardous alcohol use among pregnant women attending antenatal care at public health facilities in Gondar town, Northwest Ethiopia: A nested case-control study. PLoS One [Internet]. 2021;16(7 July):1-16. Available from: http://dx.doi.org/10.1371/journal.pone.0253162

32. Mboane R, Bhatta MP. Influence of a husband's healthcare decision making role on a woman's intention to use contraceptives among Mozambican women. Reprod Health [Intemet]. 2015;12(1):1-8. Available from: ???

33. Tekelab T, Chojenta C, Smith R, Loxton D. Factors affecting utilization of antenatal care in Ethiopia: A systematic review and metaanalysis. PLoS One. 2019;14(4):1-24. 
Figures

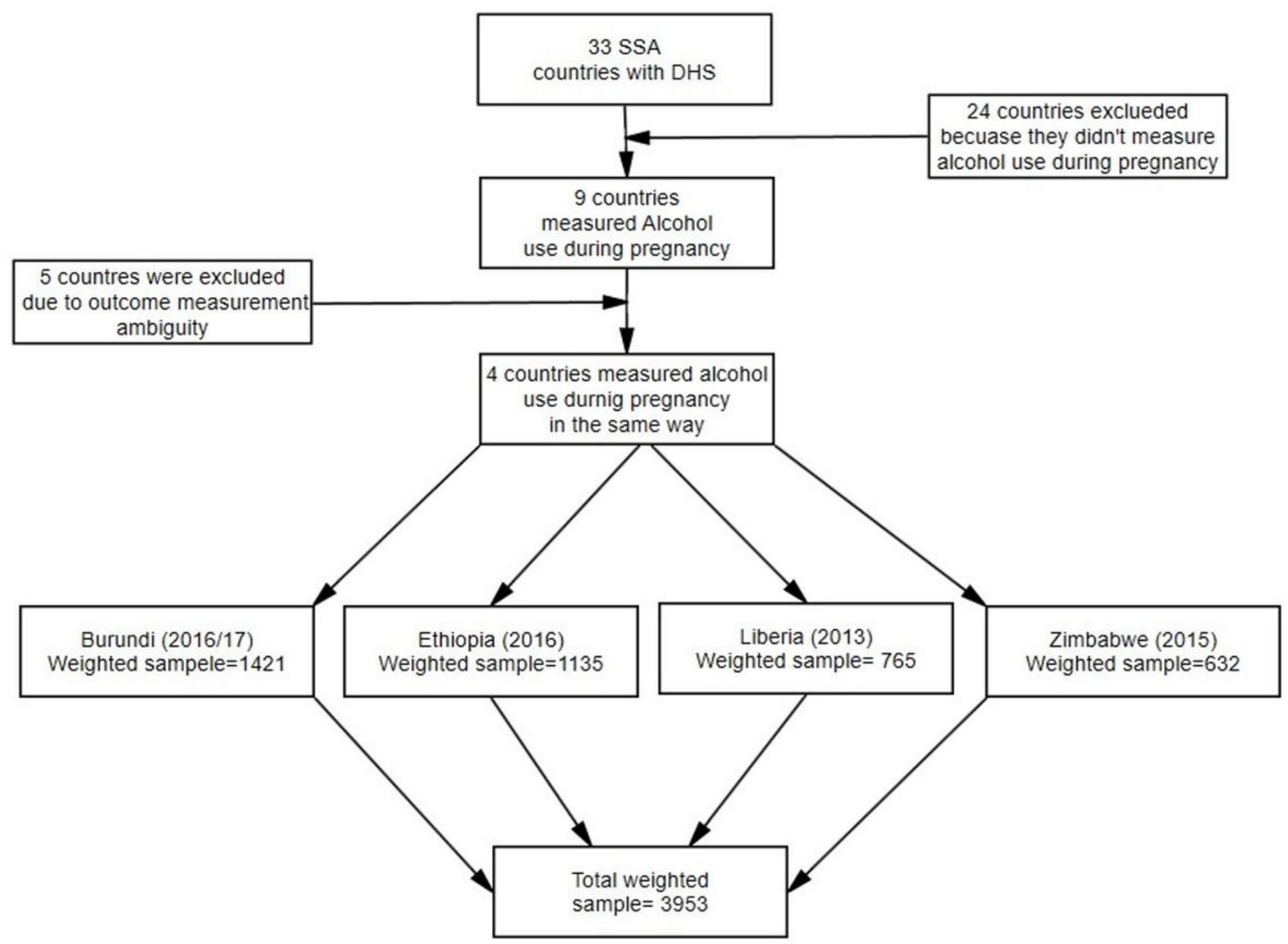

Figure 1

A diagrammatic representation of the sample extracting procedure for the study 


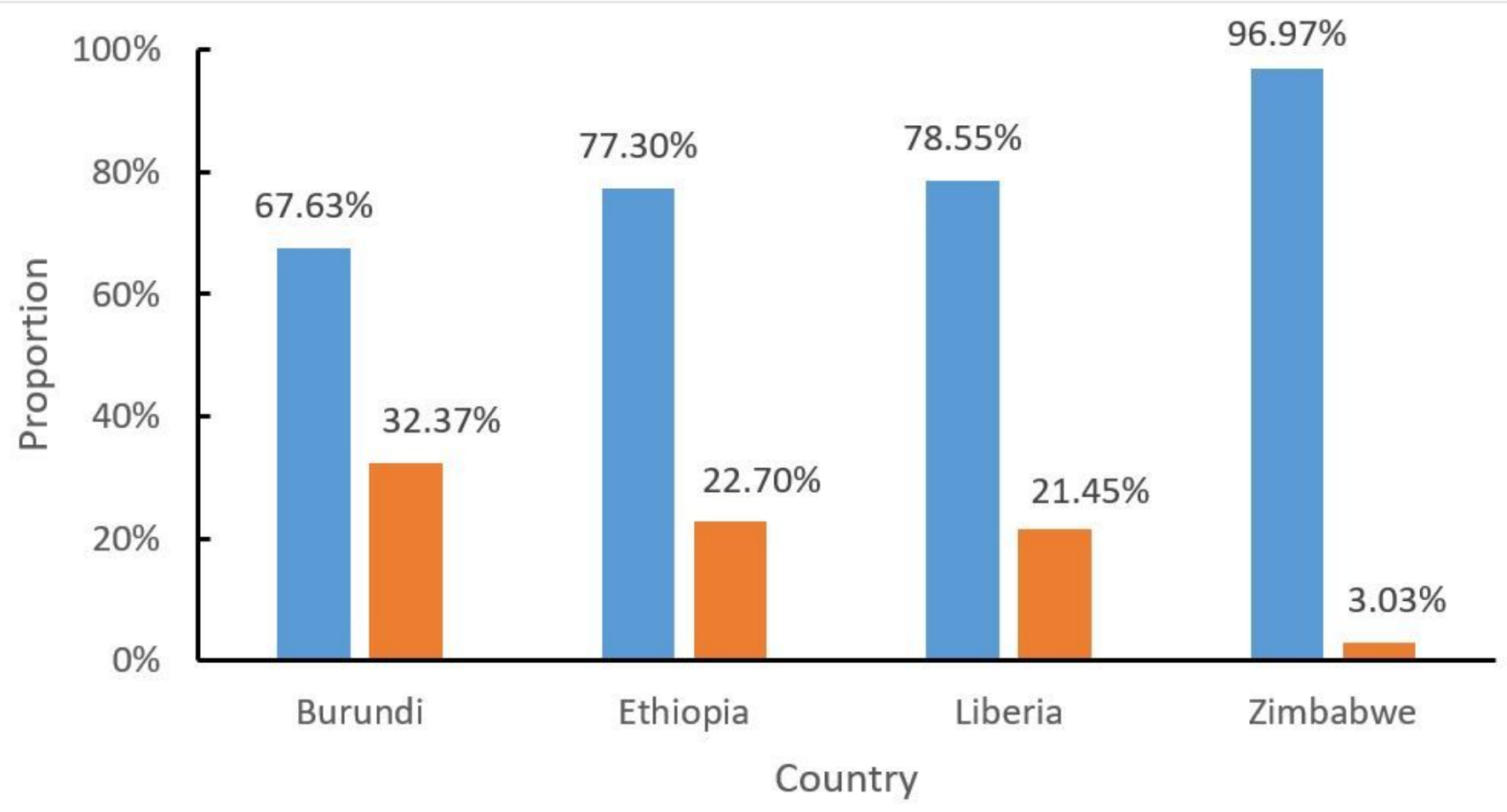

No $\square$ yes

Figure 2

Prevalence of alcohol use during pregnancy among pregnant mothers in Sub-Saharan African countries, based on the recent DHS data $(n=3,953)$. 